\title{
Modified Bell Tawse Procedure for The Management of Chronic Monteggia Fracture- Dislocations
}

\author{
*Rajiv Gogna ${ }^{1}$, Thomas Laios ${ }^{2}$ and Gunaratnam Shyamalan ${ }^{3}$ \\ ${ }^{1}$ Trauma \& Orthopaedic Surgery, University Hospital Coventry \& Warwickshire, England \\ ${ }^{2}$ Trauma \& Orthopaedic Surgery, Heart of England NHS Foundation Trust, Birmingham \\ ${ }^{3}$ Consultant Trauma \& Orthopaedic Surgery, Heart of England NHS Foundation Trust, Birmingham
}

Submission: March 19, 2017; Published: March 30, 2017

*Corresponding author: Rajiv Gogna, Specialist Registrar, Trauma \& Orthopaedic Surgery, University Hospital Coventry \& Warwickshire, Clifford Bridge Road, Coventry, CV2 2DX, England

\begin{abstract}
Chronic dislocation of the radial head following a Monteggia fracture-dislocation is a rare but potentially devastating injury resulting in longterm impaired function and movement. Early recognition and management are essential.

We present a case of a missed radial head dislocation and its subsequent management. We also review the literature and discuss the techniques described to manage this rare injury.
\end{abstract}

Keywords: Monteggia; Fracture; Dislocation; Bell Tawse; Reconstruction

\section{Case Report}

A 3-year-oldboy presented to our emergency department following a fall onto his outstretched right arm. He sustained a right ulna fracture with an anterior radial head dislocation the stereotypical Monteggia-type fracture (Figure 1). He went to theatre for open reduction and internal fixation of the ulna fracture with a plate. The radial head was successfully reduced and found to be stable hence no further stabilisation was performed.

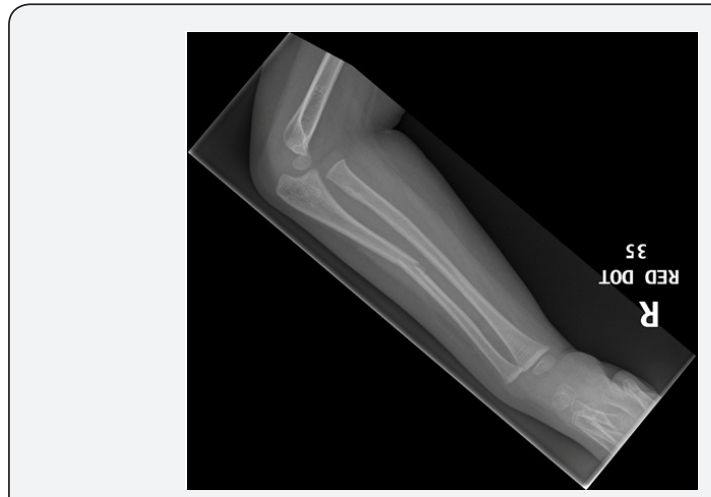

Figure 1: Radiograph showing the initial Monteggia-fracture with anterior dislocation of the radial head.
At the one-week follow-up appointment he was making a good recovery and neurovascular testing was intact. However at some point during the post-operative period the radial head dislocated anteriorly and this was missed on subsequent radiographs (Figure 2). Once the ulna fracture had united the cast was removed and as the patient was asymptomatic with a full range of movement the radiographs were not scrutinised any further.

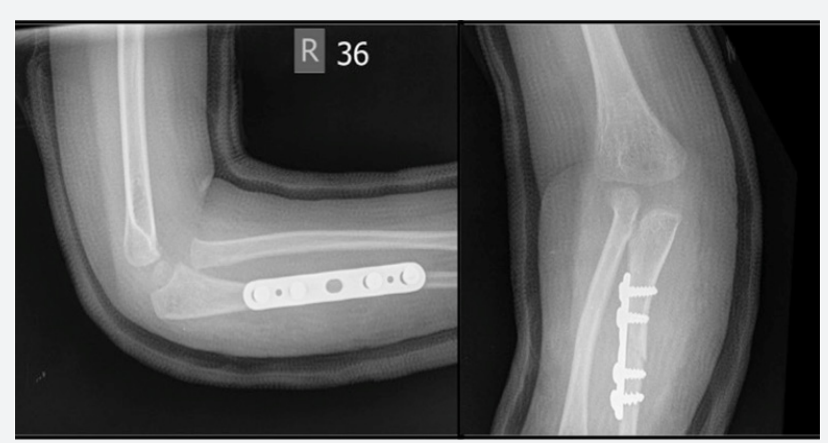

Figure 2: Radiograph showing internal fixation of the ulna fracture but closer inspection shows that the radial head remains dislocated as is does not point directly at the capitellum. 


\section{Orthopedics and Rheumatology Open Access Journal}

Nine months following the initial injury the patient was brought back for removal of metalwork and was diagnosed with a chronic radial head dislocation (Figure 3). He remained symptom-free with a well-healed scar. On examination his only restricted movement was the last 20 degrees of pronation when compared to the contralateral side.

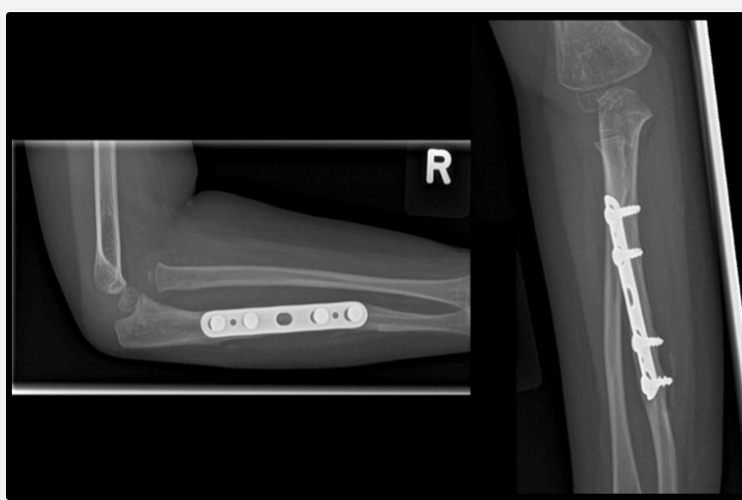

Figure 3: Radiographs taken nine months following the initial injury showing a chronic radial head dislocation.
Although he was clearly asymptomatic, as his skeleton matures the radial head dislocation would cause long-term problems with forearm rotation and elbow function. As a result the consensus was to remove the ulna plate and attempt open reduction of the radial head. If the radial head would not relocate then an ulna osteotomy would be required with the option of a transfixing wire to hold the radial head in joint. The annular ligament would also require reconstruction using a strip of triceps tendon if necessary.

During the second procedure, the ulna plate was successfully removed and the fracture had healed with good callus formation. Open reduction of the radial head was possible; hence ulna osteotomy was not required. A modified Bell Tawse procedure was performed by taking a lateral strip of the triceps tendon and anchoring it around the radial neck to reconstruct the annular ligament.

At the latest follow-up, the chronic Monteggia fracturedislocation has been corrected and the boy is asymptomatic with a full range of movement and excellent elbow function (Figures $4 \& 5)$.

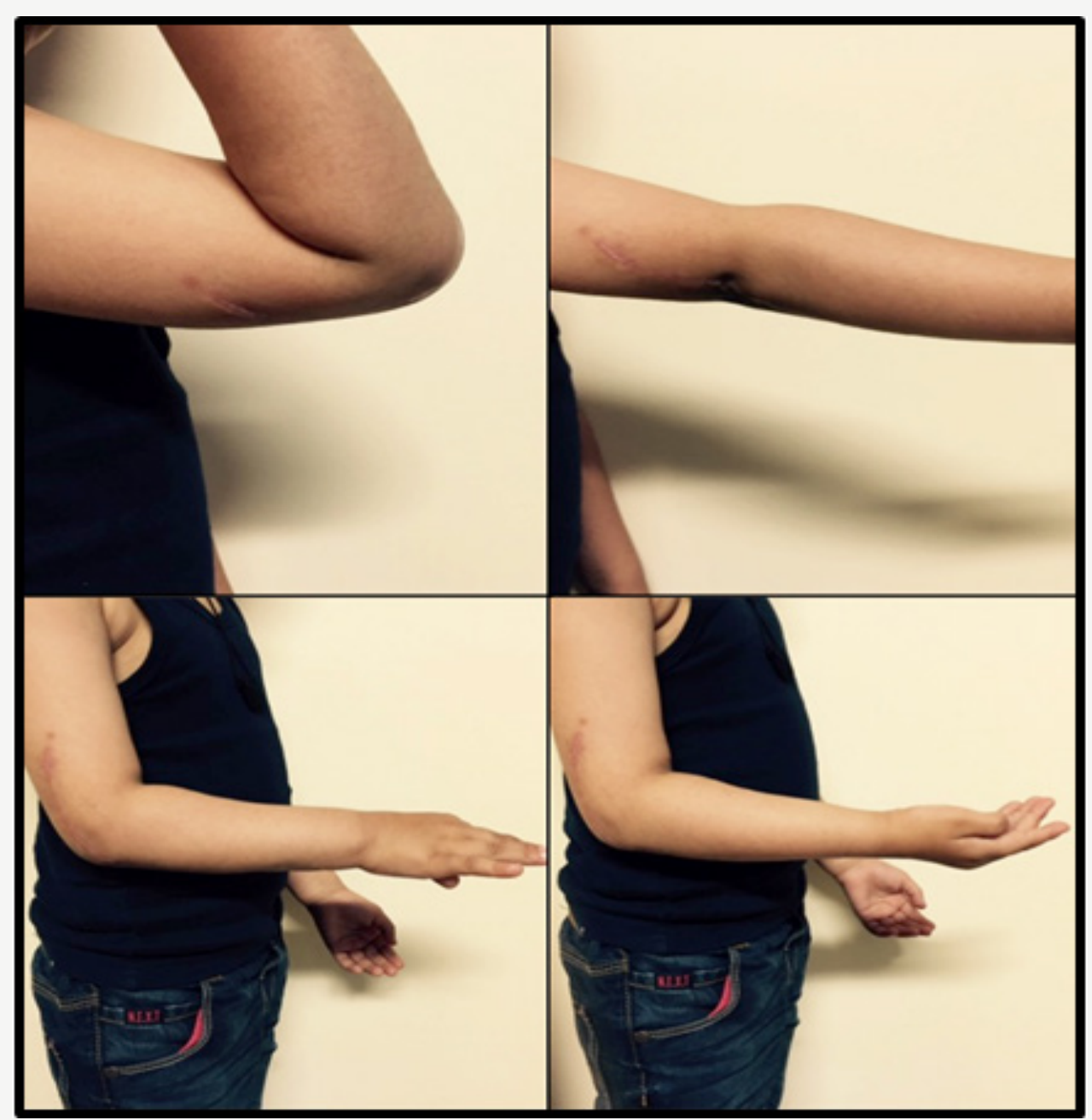

Figure 4: Clinical photographs show a well healed scar and the patient has a full range of movement following modified Bell Tawse procedure. 


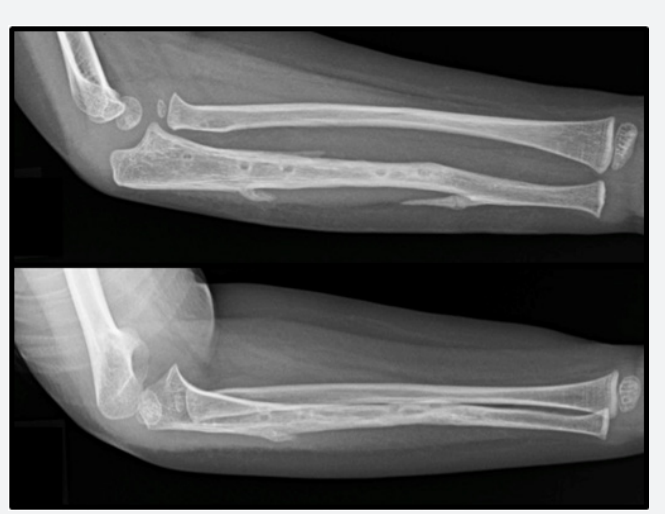

Figure 5: Final radiographs showing that following removal of metalwork and modified Bell Tawse procedure the radial head has been relocated.

\section{Discussion}

Evans et al first described the anterior Monteggia injury in 1949. Forced hyperpronation ruptures the capsule and annular ligament, followed by a fracture to the ulna shaft and finally rotation of the radial head so it lies anterior to the capsule [1]. The interposed capsule and shortening can prevent reduction of the radial head causing it to act as a mechanical block to full flexion. If left unreduced, this can result in restricted flexion, unstable cubitus valgus and ultimately a painful arthritic elbow due to secondary degenerative changes [2].

It has been described that anterior Monteggia fractures can be reduced with traction and full supination [3], but frequently this is not possible and current evidence supports the fact that open reduction is required to treat these injuries [4]. For chronic dislocations, the best clinical and radiographic results are usually obtained if the patient is less than twelve years of age or within three years following the injury as secondary changes in the head and overgrowth of the radius develop in time [5-6].

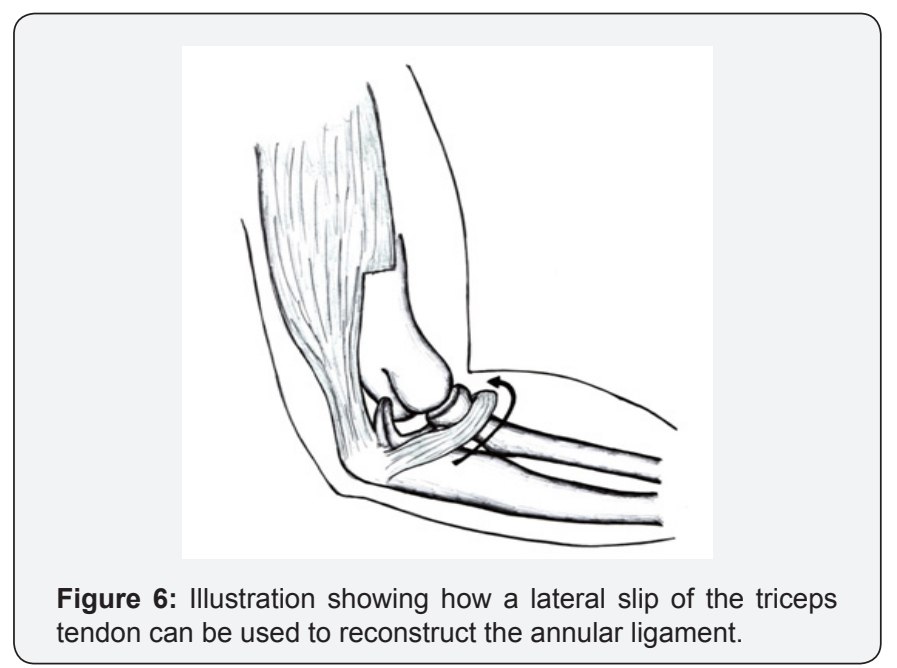

Bell Tawse originally described his technique for the treatment of malunited anterior Monteggia fractures in 1965
[7]. Using a postero-lateral approach the interposed capsular block is exposed and removed from the radiocapitellar joint. The radial head can then be easily reduced without the need to divide the ulna. Bell Tawse described reconstruction of the annular ligament by turning down a slip of the triceps tendon, leaving it attached to the ulna, and passing it around the neck of the radius from behind forward and securing it through a drill hole in the ulna (Figure 6). Rehabilitation included six weeks immobilisation in full extension and full supination followed by gradual mobilisation. In their sample of six children, reduction was easily achieved with good long-term follow-up results. Annular ligament reconstruction seems to be a simple and reproducible technique with overall good success rates reported $[5,8]$.

Since the originally described technique, several variations have been published in the literature. Lloyd-Roberts et al described reconstruction of the annular ligament using either a free palmaris longus tendon graft or a lateral slip of the triceps tendon in their sample of eight patients [9]. Reduction of the radial head was held using a transarticular Kirschner wire. The reason for using a lateral slip of the triceps tendon was because it has a rolled edge and is more substantial than the central slip. It is also anatomically closer to the radial head. They concluded that triceps slip was preferable to palmaris tendon grafting as it avoids unnecessary donor site morbidity, and also that Kirschner wire fixation seems essential to prevent subluxation or recurrent dislocation.

An important consideration when reconstructing the annular ligament is to avoid excessive tension as this may restrict rotation of the radial neck [9-10]. Hirayama et al. [11] used an ulna osteotomy with over-correction and elongation aiming to maintain the reduced position of the radial head through the stabilising action of the interosseous membrane [11]. The osteotomy is performed $5 \mathrm{~cm}$ below the olecranon, distracted by up to $1 \mathrm{~cm}$ and fixed with a 150 posteriorly angulated plate. They described good results in their series of nine patients, and if the radial head is not manually reducible due to excess deformity or chronicity of the injury, then ulna osteotomy allows reduction to be achieved. This technique has also been supported in the more recent literature $[2,5,12]$ and some authors advocate that annular ligament reconstruction is only required if the radial head remains unstable intraoperatiely [12-13].

The proximal ulna distraction-angulation osteotomy can also be held using an external fixator as described by Hasler et al. [6] The use of an external fixator allows the osteotomy to be overcorrected whilst screening the elbow under image intensifier guidance, and once the radial head is relocated the fixator can be locked. Provided there is no interposed capsule, the technique could be done percutaneously with closed reduction of the radial head avoiding the need for open reduction and ligament reconstruction [14]. 


\section{Conclusion}

It is critical that all elbow injuries and radiographs are reviewed at an early stage, as it is not uncommon for a radial head dislocation to be overlooked when there is a simple greenstick fracture of the ulna. Early reduction can prevent the long-term sequelae and complications associated with chronic Monteggia fracture-dislocations. There are severaltechniques which can be used alone or in combination to achieve relocation of the chronically dislocated radial head depending on the intraoperative findings and stability.

\section{References}

1. Evans EM (1949) Pronation injuries of the Forearm. Journal of Bone and Joint Surgery 31-B: 578.

2. Rajasekaran S, Venkatadass K (2014) Sliding angulation osteotomy": preliminary report of a novel technique of treatment for chronic radial head dislocation following missed Monteggia injuries. Int Orthop 38(12): 2519-2524.

3. Naylor A (1942) Monteggia fractures. British journal of surgery 29(115): 323.

4. Di Gennaro GL, Martinelli A, Bettuzzi C, Antonioli D, Rotini R (2015) Outcomes after surgical treatment of missed Monteggia fractures in children. Musculoskelet Surg 99 Suppl 1: S75-S82.

5. Eamsobhana P, Kaewpornsawan K (2012) Chronic Monteggia lesions treatment with open reduction and Z-lengthening technique with annular ligament reconstruction. J Med Assoc Thai 95 Suppl 9: S47-S53.
6. Hasler CC, Von Laer L, Hell AK (2005) Open reduction, ulnar osteotomy and external fixation for chronic anterior dislocation of the head of the radius. The Journal of Bone and Joint Surgery 87-B(1): 88-94.

7. Bell Tawse AJS (1965) The treatment of malunited anterior Monteggia fractures in children. The Journal of Bone and Joint Surgery 47B(4): 718-723.

8. Gyr BM, Stevens PM, Smith JT (2004) Chronic Monteggia fractures in children: outcome after treatment with the Bell-Tawse procedure. J Pediatr Orthop B 13(6): 402-406.

9. Lloyd-Roberts GC, Bucknill TM (1977) Anterior dislocation of the radial head in children. The Journal of Bone and Joint Surgery 59-B(4): 402-407.

10. Boyd JH (1970) Bunnell's surgery of the hand. $5^{\text {th }}$ edn. JB Lippincott, New York, USA, pp: 269-270.

11. Hirayama T, Takemitsu Y, Yagihara K, Mikita K (1987) Operation for chronic dislocation of the radial head in children: reduction by osteotomy of the ulna. The Journal of Bone and Joint Surgery 69-B(4): 639-642.

12. Song KS, Ramnani K, Bae KC, Cho CH, Lee KJ, Son ES (2012) Indirect reduction of the radial head in children with chronic Monteggia lesions. J Orthop Trauma 26(10): 597-601.

13. Bhaskar A (2009) Missed Monteggia fracture in children: Is annular ligament reconstruction always required? Indian J Orthop 43(4): 389395.

14. Bor N, Rubin G, Rozen N, Herzenberg JE (2015) Chronic anterior monteggia lesions in children: report of 4 cases treated with closed reduction by ulnar osteotomy and external fixation. J Pediatr Orthop 35(1): 7-10.

\section{Your next submission with Juniper Publishers} will reach you the below assets

- Quality Editorial service

- Swift Peer Review

- Reprints availability

- E-prints Service

- Manuscript Podcast for convenient understanding

- Global attainment for your research

- Manuscript accessibility in different formats

( Pdf, E-pub, Full Text, Audio)

- Unceasing customer service

Track the below URL for one-step submission https://juniperpublishers.com/online-submission.php 